\title{
Incontinence after radical prostatectomy: Anything new in its management?
}

\author{
Romain Caremel, MD; Jacques Corcos, MD, FRCSC
}

Department of Urology, Jewish General Hospital, McGill University, Montreal, QC

Cite as: Can Urol Assoc J 2014;8(5-6):202-12. http://dx.doi.org/10.5489/cuaj.1349

Published online June 16, 2014.

\section{Abstract}

Introduction: With the increasing number of radical prostatectomies (RP) performed, male stress urinary incontinence (SUI) has become common. The artificial urinary sphincter (AUS) is the gold standard to treat SUI post-RP, but new devices have recently been developed. We review the recent studies on the treatment of SUI post-RP; we also describe the surgical techniques, mechanisms of action and results of these new procedures.

Methods: We conducted a literature review search in the PubMed/ Medline and Embase databases. Our search was restricted to recent articles. We included studies even if the urinary incontinence was due to sphincter deficiency after RP in non-neurologic patients.

Results: We found 8 cohort studies for the surgical procedure: 3 studies concerning slings, 1 involving balloons adjustable implant, and 4 involving new devices. The only randomized controlled trial (RCT) was a pharmacologic clinical trial comparing duloxetine to placebo. The social continence rates were analyzed for 6 studies and were up to $66 \%$.

Conclusion: New minimally invasive surgical procedures have emerged as the main alternative to AUS, with social continence rates up to $60 \%$ despite just 1 RCT studying the pharmacologic approach. There is an urgent need for well-designed clinical trials to clarify the role of new surgical alternatives in the management of SUI post-RP. New technologies should continue to be evaluated and compared with the AUS, which remains the gold standard.

\section{Introduction}

With the increasing number of radical prostatectomies $(\mathrm{RP})$, male stress urinary incontinence (SUI) has become common. Data from large multicentre studies and prostate cancer databases suggest that following RP, $1 \%$ to $40 \%$ of patients complain of persistent urinary incontinence (UI). ${ }^{1-4}$ Large cohort studies indicate that between $6 \%$ and $9 \%$ of patients undergo subsequent surgical treatment for post- prostatectomy incontinence $(\mathrm{PPI}) .^{5-8} \mathrm{UI}$ is one of the most feared complications of RP as it strongly affects a patient's quality of life.

Most authors define SUI as persistent SUI 1 year after prostatic surgery in the setting of conservative therapy failure. ${ }^{9}$ The artificial urinary sphincter (AUS) (AMS800) implantation provides high rates of long-term continence and patient satisfaction, and is currently considered the gold standard for the treatment of PPI. ${ }^{10,11}$

However, a recent investigation by Kumar and colleagues ${ }^{12}$ showed that many patients prefer treatment with a non-mechanical device. To keep the good success rates and improve some of the disadvantages of the AUS (i.e., high cost, complications, relative difficult insertion), new devices have been developed. The rationale for the management of PPI has been challenged by newly published data, which have enlarged the armamentarium with less-invasive therapies.

We review the recent studies about the treatment of SUI post-RP and we describe the surgical techniques, the mechanisms of action and the results of these new procedures.

\section{Methods}

We conducted a literature search in the Pub Med/Medline and Embase databases. We used "male urinary incontinence," "post-prostatectomy" and "treatment" as our keywords. Our literature search was restricted to English articles published in the last 15 months. We included studies even if the UI was due to sphincter deficiency after RP in nonneurologic patients. We excluded studies which reported on a combined surgical procedure. Articles were selected based on their study design, baseline patient evaluation, reports of perioperative data, study primary outcome criteria, definition of success, follow-up and safety, and efficacy results. Efficacy and safety results were reported and a pooled analysis was conducted on the following end points: infection/erosion rates, explantation rate, social continence 
rate (defined as the proportion of patients wearing no pad or 1 pad per 24 hours), and dry rate (defined as the proportion of patients wearing no pads). The data were extracted by a single person and thereafter quality-controlled by a second person.

\section{Results}

We included 9 articles with specific data about treatment of 761 patients with non- neurogenic SUI after prostatic surgery. From these patients, 91\% experienced PPI and 13.8\% received adjuvant radiotherapy (RT). The mean follow-up was 25.2 months (range: $3-46.8$ ). We found 8 cohort studies for the surgical procedure: 3 studies concerning slings, 1 involving balloons adjustable implant, and 4 with new devices (ZI 375 artificial urinary, an adjustable transobturator hydraulic male system [ATOMS], a periurethral constrictor [Silimed] and the virtue quadratic sling). The only randomized controlled trial (RCT) was a pharmacologic clinical trial comparing duloxetine to placebo. The primary outcome, except in 1 study, was based on pad usage. The definition of success was different for each study, except for the 3 studies, which were defined by using none or 1 pad for security reasons (social continence). The social continence rates were analyzed for 6 studies and were up to $66 \%$ (Table 1 ).

\section{Duloxetine}

Duloxetine, a serotonin-noradrenalin reuptake inhibitor, has shown its efficacy for SUI management in women ${ }^{13}$ and has been proposed for use in men. This product acts in the Onuf's nucleus by blocking the reuptake of noradrenalin and serotonin. The increased concentration of these two neurotransmitters raises the activity of pudendal motor neurons, leading to an increase in striated urethral sphincter tonus and detrusor relaxation. ${ }^{14}$

Cornu and colleagues ${ }^{15}$ conducted the first prospective, placebo-controlled, double blind, randomized, superiority study in 31 men with mild to moderate SUI persistent at least 1 year after RP. The primary outcome was the relative variation in the mean number of leakage episodes per day (IEF), according to the voiding diary. Secondary outcome measures concerning efficacy were the variation in symptom questionnaires (Urinary Symptom Profile, International Consultation on Incontinence Questionnaire-Short Form [ICIQ-SF]), the variation in the 1 -hour pad test, and the variation in the quality-of-life questionnaires (I-QoL, Incontinence Impact Questionnaire-Short-Form, Urogenital Distress Index-Short Form and ICIQ-SF).

A total of 31 men were randomized to duloxetine $(n=16)$ or placebo $(n=15)$. The decrease in IEF at the end of the study was significantly greater in the duloxetine group $(-52.2 \% \pm 38.6$ vs. $+19.0 \% \pm 43.5$; mean difference: $71.2 \%$;
95\% confidence interval [Cl] (41.0-101.4); $p<0.0001)$ (Fig. 1). Significant, superior IEF improvements with duloxetine compared to placebo were observed after 8 weeks and 12 weeks, but not at the 4 weeks follow-up.

Quality of life, measured by the I-QoL questionnaire, was improved in the duloxetine group compared to placebo. However, this difference was only significant after 12 weeks of treatment $(p=0.019)$. Other secondary parameters concerning efficacy, except for the 1-hour pad test, showed a significant improvement in the duloxetine group.

The main adverse event associated with duloxetine was fatigue ( $50 \%$ of patients on duloxetine). Although adverse events in this study did not require treatment interruption or specific medical management, the maximum flow rate (Qmax) and the post-void residual (PVR) volume were not significantly different from baseline in any study group.

\section{Slings}

Analogous to the successful use of sling surgery in women, slings have been developed for use in men with PPI. A variety of tapes are available and the procedure is based on the concept of passive external urethral compression. The bone-anchored InVance sling (American Medical Systems) was the first sling technically described.

In 2012, the results of 3 different slings have been published: 1 with a re-ajustable sling system (The Argus system) that allows implant adjustment and regulation of the desired tension, and 2 transobturator slings (The AdVance male sling and I-STOP-TOMS sling).

\section{The Argus system}

In the Argus system (Promedon SA, Cordoba, Argentina), the rings are positioned on the columns, resting on the rectus

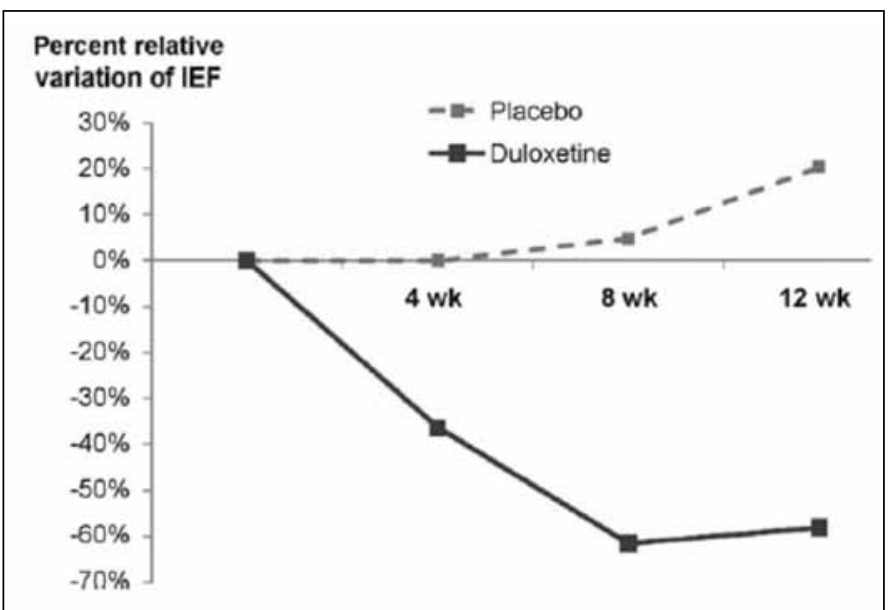

Fig. 1. Median percent decrease in incontinence episodes frequency (IEF) for duloxetine and placebo at each of the three visits conducted during follow-up. The difference between duloxetine and placebo response was significant at visit 4 (8 weeks) and visit 5 ( 12 weeks). 


\begin{tabular}{|c|c|c|c|c|c|c|c|c|c|c|}
\hline Studies & $\mathbf{N}$ & $\begin{array}{c}\% \text { RPI } \\
\text { other } \\
\text { prostatic } \\
\text { surgery }\end{array}$ & $\begin{array}{c}\text { Previous } \\
\text { adjuvant } \\
\text { RT, \% }\end{array}$ & $\begin{array}{l}\text { Severity of UI } \\
\text { at baseline }\end{array}$ & $\begin{array}{l}\text { Definition of } \\
\text { success }\end{array}$ & $\begin{array}{c}\% \\
\text { Success }\end{array}$ & $\begin{array}{c}\text { Social } \\
\text { continence }\end{array}$ & $\begin{array}{l}\text { Dry } \\
\text { rate }\end{array}$ & $\begin{array}{c}\text { Complications, } \\
\%\end{array}$ & $\begin{array}{c}\text { Mean } \\
\text { follow-up }\end{array}$ \\
\hline $\begin{array}{l}\text { Advance sling, } \\
\text { Rehder et al. }{ }^{18}\end{array}$ & 156 & $92.9 \%$ & $14.1 \%$ & $\begin{array}{c}\text { Mild or } \\
\text { moderate: } \\
64.1 \% \\
\text { Severe: } \\
35.3 \%\end{array}$ & $\begin{array}{l}\text { Cured: } 0 \text { or } \\
1 \text { pad for } \\
\text { security } \\
\text { reasons }\end{array}$ & $76.8 \%$ & $76.8 \%$ & $?$ & $\begin{array}{c}\text { Explantation: } \\
0.64 \% \\
\text { Erosion: } 0 \% \\
\text { Infection: } 0.64 \% \\
\text { Transient UR: } \\
9 \%\end{array}$ & 3.9 years \\
\hline $\begin{array}{l}\text { I-STOP sling, } \\
\text { Grise et al. }{ }^{17}\end{array}$ & 122 & $94.9 \%$ & $0 \%$ & $\begin{array}{l}\mathrm{ICl} \text { modular } \\
\text { questionnaire } \\
\text { score: } 4-16\end{array}$ & Dry: 0 pads & $59.4 \%$ & $79.7 \%$ & $59.4 \%$ & $\begin{array}{l}\text { Explantation: } \\
0 \% \\
\text { Erosion: } 0 \% \\
\text { Acute UR: } 0 \% \\
\text { Voiding of the } \\
\text { CC: } 4 \%\end{array}$ & $\begin{array}{c}\text { At } 12 \\
\text { months }\end{array}$ \\
\hline $\begin{array}{l}\text { Argus sling, } \\
\text { Hubner et al. }{ }^{18}\end{array}$ & 101 & $86.1 \%$ & $21.8 \%$ & $\begin{array}{l}\text { Moderate } \\
\text { (2 PDD) or } \\
\text { severe } \\
\text { (>2 PPD) }\end{array}$ & $\begin{array}{l}\text { Dry: } 20-\min \\
\text { pad test with } \\
0-1 \mathrm{~g}\end{array}$ & $79.2 \%$ & $79.2 \%$ & $69.3 \%$ & $\begin{array}{c}\text { Explantation: } \\
15.8 \% \\
\text { Erosion: } 12.87 \% \\
\text { Infection: } 3 \%\end{array}$ & 2.1 years \\
\hline $\begin{array}{l}\text { Balloons } \\
\text { ProACT, } \\
\text { Rouprêt et al. }{ }^{20}\end{array}$ & 128 & $93.75 \%$ & $25 \%$ & $\begin{array}{l}\text { Moderate: } \\
55.5 \% \\
\text { Mild: } 32.25 \% \\
\\
\text { Severe: } \\
13.25 \%\end{array}$ & $\begin{array}{l}\text { Cured: } 0 \text { or } \\
1 \text { pad for } \\
\text { security } \\
\text { reasons }\end{array}$ & $66 \%$ & $66 \%$ & $?$ & $\begin{array}{c}\text { Explantation: } \\
18 \% \\
\text { Erosion/ } \\
\text { infection: } 8.5 \% \\
\text { Migration: } 5.4 \% \\
\text { Urethral } \\
\text { or bladder } \\
\text { perforation: } 4 \%\end{array}$ & $\begin{array}{c}56.3 \\
\text { months }\end{array}$ \\
\hline $\begin{array}{l}\text { ZSI } 375 \text { AUS, } \\
\text { Staermann et } \\
\text { al. }^{23}\end{array}$ & 36 & $77 \%$ & NR & $\begin{array}{l}\text { Moderate to } \\
\text { severe (all } \\
\text { patients used } \\
\geq 2 \text { PPD) }\end{array}$ & $\begin{array}{l}\text { Cured: } 0 \text { or } \\
1 \text { pad for } \\
\text { security } \\
\text { reasons }\end{array}$ & $79 \%$ & $79 \%$ & $29 \%$ & $\begin{array}{c}\text { Explantation: } \\
11 \% \\
\text { Erosion: } 2.7 \% \\
\text { Infection: } 8.3 \% \\
\text { Bladder } \\
\text { overactivity: } 0 \% \\
\text { Chronic UR: } 0 \%\end{array}$ & $\begin{array}{c}15.4 \\
\text { months }\end{array}$ \\
\hline $\begin{array}{l}\text { Adjustable } \\
\text { transobturator, } \\
\text { ATOMS, Hoda } \\
\text { et al. }{ }^{22}\end{array}$ & 99 & $92.9 \%$ & $31.3 \%$ & $\begin{array}{l}\text { Moderate: } \\
\text { 29.3\% } \\
\text { Severe: } \\
70.7 \%\end{array}$ & $\begin{array}{c}\text { Cured: } 0 \\
\text { pads and } \\
24-\mathrm{h} \text { pad test } \\
<10 \mathrm{~mL}\end{array}$ & $?$ & $?$ & $63 \%$ & $\begin{array}{l}\text { Explantation: } \\
4 \% \\
\text { Erosion: } 0 \% \\
\text { Infection: } 4 \% \\
\text { Migration: } 0 \% \\
\text { Temporary UR: } \\
2 \%\end{array}$ & $\begin{array}{c}17.8 \\
\text { months }\end{array}$ \\
\hline $\begin{array}{l}\text { Duloxetine } 80 \\
\mathrm{mg} / \text { day, Cornu } \\
\text { et al. }{ }^{15}\end{array}$ & 31 & $100 \%$ & $0 \%$ & $\begin{array}{l}\text { 7-28 leakage } \\
\text { episodes per } \\
\text { week }\end{array}$ & $\begin{array}{l}\text { Reduction in } \\
\text { incontinence } \\
\text { episodes } \\
\text { compared to } \\
\text { placebo }\end{array}$ & $?$ & $?$ & $?$ & $\begin{array}{c}\text { Fatigue: } 50 \% \\
\text { Sweat: } 25 \% \\
\text { Insomnia: } 25 \% \\
\text { Loss of libido: } \\
19 \%\end{array}$ & 12 weeks \\
\hline
\end{tabular}

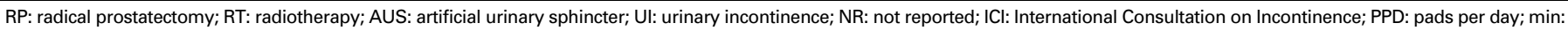
minute; h: hour; UR: urinary retention; CC: corpus cavernosum.

fascia to regulate the tension of the silicone cushion on the bulbar urethra (Fig. 2). The coned structure of the columns allows adjustment of sling tension by tightening or releasing the 2 silicone rings. The tension is adjusted to achieve a retrograde leak point pressure (RLPP) of $45 \mathrm{cmH}_{2} \mathrm{O}$. Sling tension is correct if the cystoscopy shows coaptation of the bulbar urethra and a stop of the water drip with the water level at $45 \mathrm{~cm}$ from the pubic bone. 


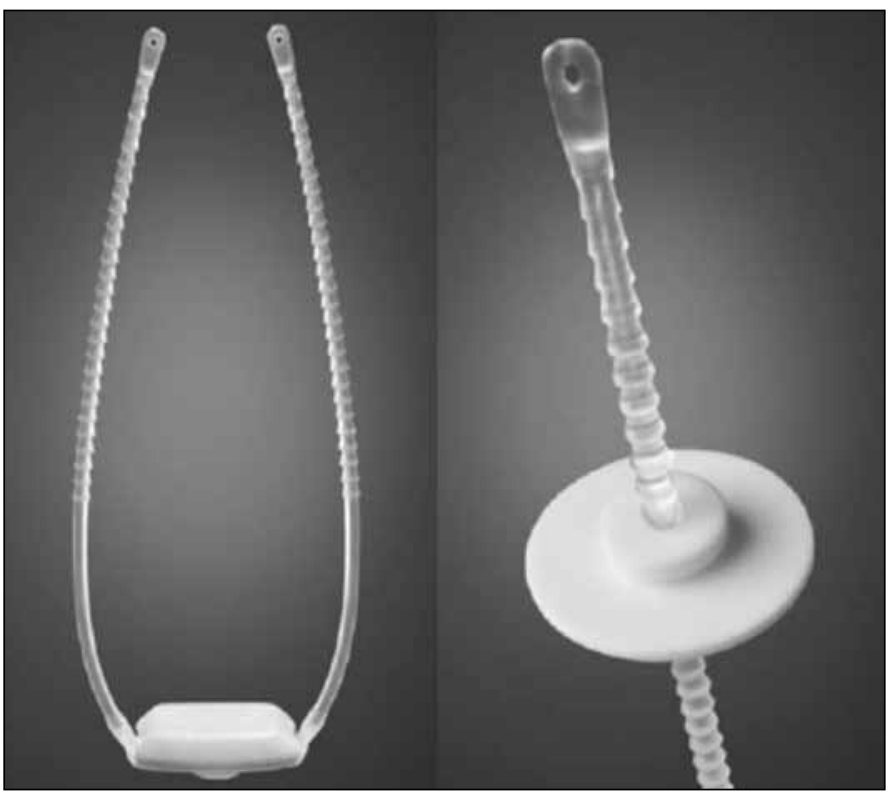

Fig. 2. Argus system (Promedon SA; Cordoba, Argentina) including silicone cushion, 2 silicone columns and silicone rings/washers.

Hübner and colleagues ${ }^{16}$ reported the results of 101 patients treated with the Argus sling for SUI. The mean patient age was 69.6, with moderate (2 pads/day [PPD]) to severe SUI (>2 PPD). Most men $(86.1 \%)$ were incontinent after RP. Of these men, $22(21.8 \%)$ were treated with RT for local recurrence of prostate cancer before the Argus implantation. The sling was positioned with a mean RLPP of 37 (20-48) $\mathrm{cmH}_{2} \mathrm{O}$. Adjustment was necessary in 39 cases $(38.6 \%)$ after an average of 104.3 days: 10/101 patients $(9.9 \%)$ required loosening under general anaesthesia, 29/101 patients $(28.7 \%)$ required tightening under local anaesthesia. An additional adjustment to the sling tension was made in 7 patients $(6.9 \%)$. A third adjustment to the position of the columns and washers was necessary in 3 patients (3\%) due to migration of the washers or rupture of a column after an average of 313 days. One patient required a fourth adjustment after 760 days.

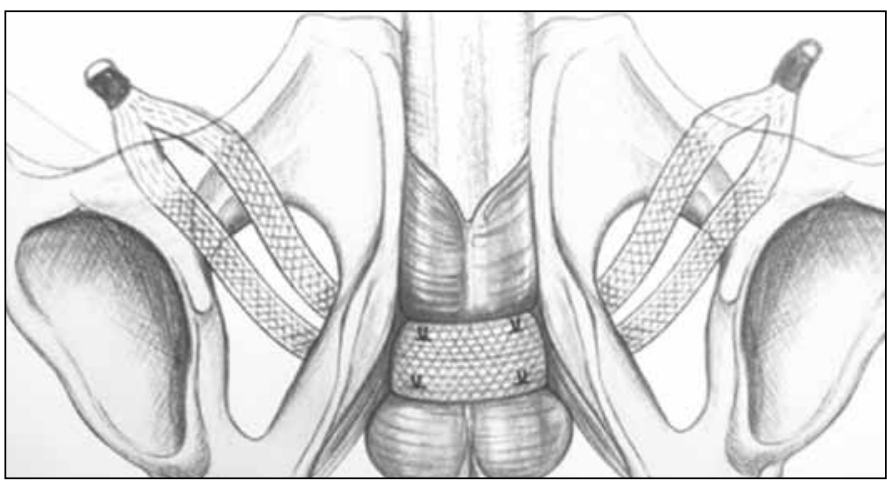

Fig. 3. Suburethral 1-STOP TOMS (CL Medical) is a monofilament polypropylene (macropores $>75 \mu \mathrm{m}$ ) nonextensible 4-arm sling (2 arms on each side). Dimensions are $45 \mathrm{~cm} \times 1.4 \mathrm{~cm}$, with a $2.8-\mathrm{cm}$ central part placed over urethra.
After a median follow-up of 2.2 years, 80/101 (79.2\%) patients were considered dry, with a pad test of $0-1 \mathrm{~g}$. The I-QoL score increased from the initial mean of 28.8 (range: $14.5-61.8)$ to 63.2 (range: $16.4-115)$ points $(p<0.001)$. Sixteen patients $(15.8 \%)$ had complications requiring device removal due to urethral erosion or infection after a mean of 371.1 (range: 20-1260) days. Of these patients, 3 had been treated previously with RT for local recurrence of prostate cancer, and 2 had been diagnosed and treated with incision of urethral strictures or bladder neck stenosis before the Argus implantation.

\section{I-STOP TOMS transobturator male sling}

The 4-arm I-STOP TOMS transobturator male sling $(\mathrm{CL}$ Medical) is a monofilament polypropylene (pores $>75 \mu \mathrm{m}$ ) non-extensible 4-arm large sling (Fig. 3). The dimensions are $45 \times 1.4 \mathrm{~cm}$, with a $2.8-\mathrm{cm}$ central part placed over the urethra.

Grise and colleagues ${ }^{17}$ reported the first study presenting prospective data on the efficacy and tolerability of the I-STOP TOMS male sling. Eligible patients had SUI related to prostatectomy (radical for $94.9 \%$ ) performed $>6$ months before study entry. In addition, they were unresponsive to, or refused, urinary physiotherapy, and had a UI score of 4 to 16 using the $\mathrm{ICl}$ Modular Questionnaire-Urinary incontinence short form (score range $0-21$ ). Patients were excluded if they had a history of prostate RT. A total of 122 patients were included from 30 centres in France. The results included only those patients with 12 months of follow-up (103/120 patients). The number of pads used daily at baseline and at 12 months was available for 69 patients. At 12 months, 60 $(87.0 \%)$ of the 69 patients had improvement in the number of pads used daily: $41(59.4 \%), 14(20.3 \%)$, and $5(7.3 \%)$ patients reported 0,1 , and $>1$ PPD, respectively. However, 9 patients $(13.0 \%)$ had no improvement, with 7 (10.1\%) and $2(2.9 \%)$ reporting 1 and $>1$ PPD, respectively. Pad use at 12 months had decreased significantly compared with

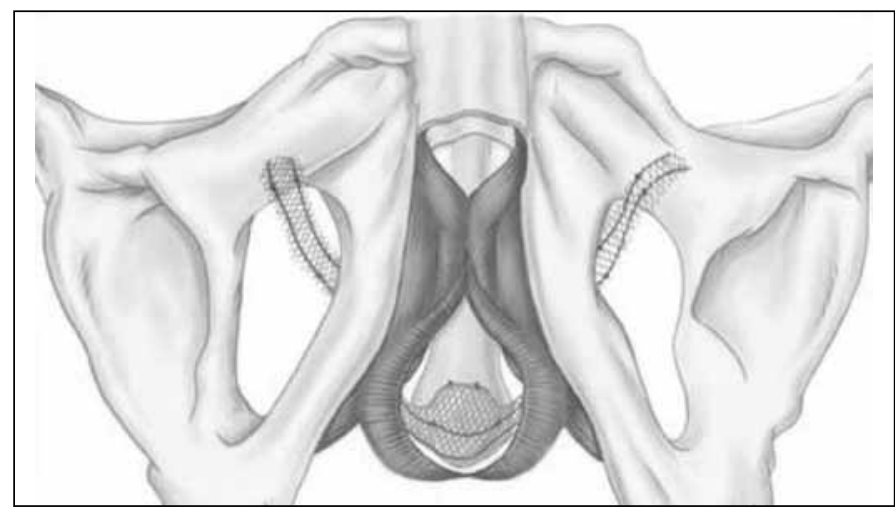

Fig. 4. The $A d V a n c e^{T M}$ male sling (American Medical Systems, Minnesota, MN, USA). 
that at baseline (mean 0.6 vs. $2.4, p<0.001$; $\mathrm{n}=69$ ).

At the 12-month follow-up, all symptoms and bother scores, as assessed by the urinary function short form (Prostate Cancer Index, University of California, Los Angeles, CA) and the urinary incontinence short form $(\mathrm{ICI}$ Modular Questionnaire), were significantly improved statistically compared with the scores at baseline. In addition, $91.2 \%$ of patients were "satisfied" or "very satisfied"

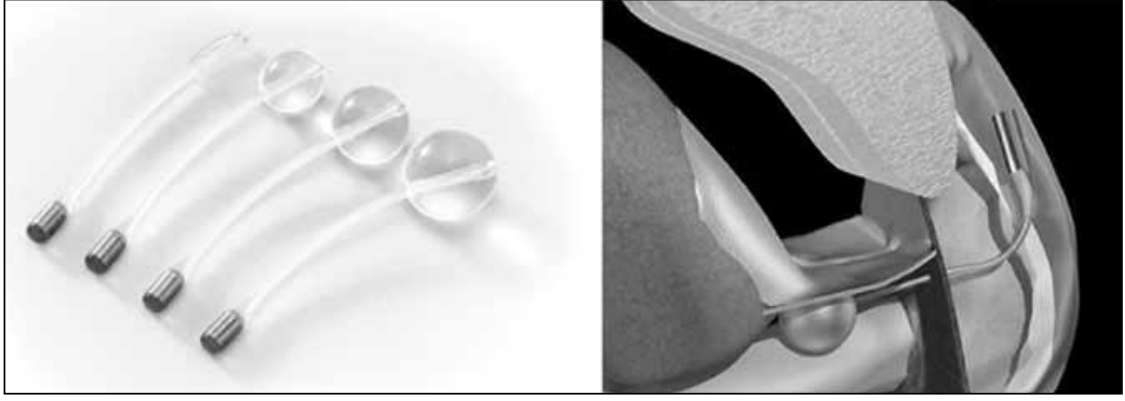

Fig. 5. 2 ballons ProACT'M (Medtronic, USA) placed percutaneously bilaterally at the bladder neck. with treatment.

No complications, such as bladder perforation, intraoperative bleeding ( $>200 \mathrm{~mL}$ ), nerve, bowel, or vascular injury occurred during the intervention, except for wounding of the corpus cavernosum ( $4.0 \%$ of the patients). The Qmax rates were similar before and after surgery. Acute urinary retention or urethral erosion did not occur.

\section{AdVance transobturator male sling}

The AdVance male sling (American Medical Systems, Minnetonka, $\mathrm{MN}$ ) is a polypropylene monofilament mesh placed retro urethrally under the proximal part of the urethral bulb, passing bilaterally through the obturator fossa (Fig. 4). By compensating for the postprostatectomy laxity of posterior supporting structures, the sling essentially realigns the anatomy of the urethral sphincter complex towards the normal, preprostatectomy configuration.

Rehder and colleagues ${ }^{18}$ reported the first results of 3 years of follow-up data in a large multi- institutional series of patients $(n=156)$ treated with the AdVance male sling for SUI. The primary outcome was based on pad usage over a 24-hour period at the 3-year visit. Patients were classified as cured based on no pad or 1 dry pad for security reasons or as improved if 1 or 2 PPD were used and if there was a reduction in daily pad usage of $50 \%$. All other pad usage, as well as those patients who required an additional procedure was classified as failure. Secondary efficacy outcomes were patient satisfaction involving the ICIQ-SF and the I-QOL questionnaires. Perioperative and postoperative complications were also recorded using the Dindo classification.

Most patients (92.9\%) had previously undergone RP, the mean duration of which was 3.9 years prior to insertion of the sling, and a small percentage of patients had received adjuvant RT (14.1\%). Most had mild or moderate incontinence $(64.1 \%)$ at baseline; $35.3 \%$ had severe incontinence.

Outcomes at 1 and 3 years indicate that pad usage was significantly decreased compared with baseline $(p<0.0001)$. At 1 -year, $76.9 \%$ of patients could be classified as cured or improved, and this outcome was maintained at 3 years at $75.7 \%$. Postoperatively, there was no change in median Qmax and PVR at 1 and 3 years.
In the univariable models, pre-treatment pad usage and severity of incontinence had a significant impact on success. However, in the multivariable model, only pre-treatment pad usage was an independent predictor of success (odds ratio: $1.149 ; 95 \% \mathrm{Cl} 1.009-1.307 ; p=0.0355)$. In contrast, previous irradiation $(p=0.0723)$ and age $(p=0.6662)$ had no impact on outcome. In terms of the severity of incontinence and its impact on quality of life, data on 101 patients from 2 centres at 3-year follow-ups indicated improvements in both questionnaires used. The ICIQ-SF score for questions 1 to 3 decreased from a baseline median value of 17.0 (interquartile range [IQR]: 14.0-19.0) to 7.0 (IQR: 3.0-14.0), while the I-QOL score increased from 61.0 (IQR: 45.0-71.0) to 93.0 (IQR: 72.0-105.0).

No perioperative complications were reported in the patient cohort. In total, 109 complications were registered, mostly Dindo grade I $(n=90)$. The most common complication was mild perineal pain, but this issue resolved spontaneously in 6 months. The one sling explantation was conducted because of symphysitis. This was the only late complication. No erosions or loss of erectile function was registered. The transient urinary retention rate was $9 \%$ in this study.

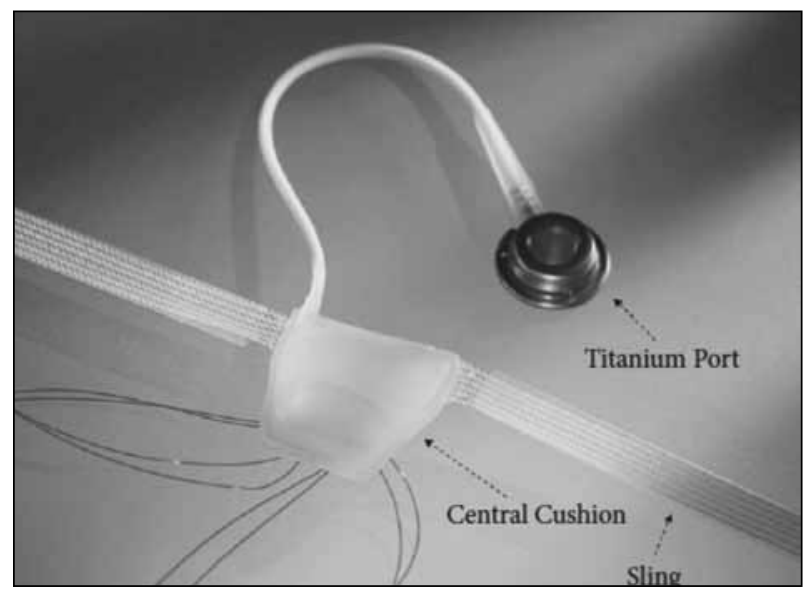

Fig. 6. The $A M O M S \AA$ device (AMI, Vienna, Austria): the mesh implant with integrated adjustable cushion and the implantable titanium port for adjusting cushion volume. 


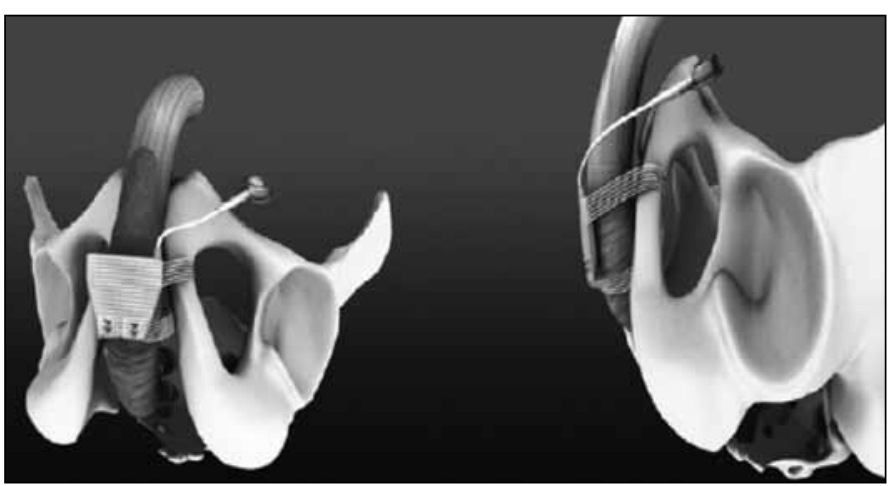

Fig. 7. Image showing placement of the ATOMS $®$ device: the self-anchoring adjustable system supports the bulbar urethra using the transobturator approach. It compresses only the ventral aspect of the bulbar urethra, leaving the dorsal and lateral blood flow intact.

\section{Balloons}

In 2005, Hübner and Schlarp published the concept of static, progressive and adjustable external non-circumferential urethral compression by placing 2 balloons percutaneously bilaterally at the bladder neck. ${ }^{19}$

Recently, Rouprêt and colleagues ${ }^{20}$ determined the functional results and morbidity of the balloon ProACT (Medtronic) implants (Fig. 5) to treat male SUI after prostate surgery. Daily pad counts were recorded as a measure of the severity of incontinence at baseline. Incontinence was evaluated as PPD used by patients, and was ranked as mild (1 or 2 PPD), moderate ( 3 to 5 PPD) and severe (more than 5 PPD or use of condom catheter). Continence was assessed postoperatively according to changes in pad counts. Success was defined as no pad or 1 security PPD, and failure was defined as more than 1 PPD or change of treatment.

A total of 128 patients were prospectively included in the study with a mean follow-up of 56.3 months. The mean patient age was 71. Of these patients, 120 experienced PPI and 8 presented with SUI after transurethral resection of the prostate (TURP). A history of adjuvant RT after RP was found in 30 patients $(25 \%)$. Thirteen patients $(10 \%)$ had undergone prior anti-incontinence surgery with the AUS AMS800, ${ }^{10}$ InVance Male Sling System ${ }^{1}$ and Macroplastique (Uroplasty Inc.) injections. ${ }^{2}$

At the end of follow-up, the baseline daily pad count decreased from a mean of 4.2 to $1.46(p<0.005)$. The mean number of balloon adjustments was 2.33 (range: $0-5)$ and the mean final volume per balloon was $4.46 \mathrm{~mL}$ (range: 1-8). In total, 85 patients were dry, and the functional result was scored as a success in $67 \%$ and $66 \%$ of patients at 1 and 2 years, respectively. The functional result was considered successful in $68 \%$ of patients with mild/ moderate incontinence at baseline versus $60 \%$ of patients with severe incontinence initially $(p<0.02)$. The failure rate was $54 \%$ among the 30 patients treated with RT before

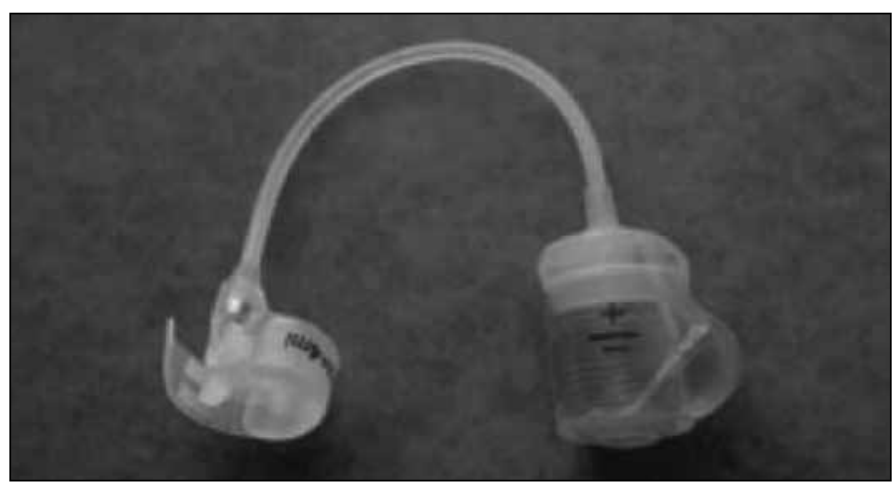

Fig. 8. The preconnected two part ZSI 375 artificial urinary (Zephyr Surgical Implants, Geneva, Switzerland).

the ProACT implantation versus $27 \%$ for those not treated with RT $(p<0.02)$.

Several complications were observed during follow-up, including acute urinary retention at the time of adjustment $(n=2)$, urethral erosions $(n=11)$, migrations $(n=7)$ or balloon perforation $(n=6)$. Six urethral erosions occurred during the first year after implantation. A total of 17 revision procedures were performed: 6 patients had to have their balloons replaced or repositioned due to complications of perforated balloons and 7 for balloon migration. An additional 4 patients had iterative repositioning procedures. At the end of follow-up 23 (18\%) balloons were explanted and $17(74 \%)$ of the explanted balloons were re-implanted. In 4 cases of urethral erosion, the ProACT system was removed and subsequently replaced by an AUS. A statistically significant association was observed between urethral erosion and a history of RT ( $p<0.005)$, and between urethral erosion and functional failure $(p<0.05)$.

\section{The adjustable transobturator hydraulic male system}

The adjustable transobturator hydraulic male system (ATOMS, AMI, Vienna, Austria) was designed and introduced in Europe in March 2009. It is a self-anchoring adjustable system to support the bulbar urethra using the transobturator approach. ${ }^{21}$ The ATOMS device has 2 components: the mesh implant with integrated adjustable cushion, and the implantable titanium port for adjusting the volume of the cushion at any time (Fig. 6). The silicone cushion is located in the middle of the mesh tape and filled via the low-profile port and catheter both intra- and postoperatively (Fig. 7). The mesh (sling) is built of macroporous, monofilament polypropylene.

Hoda and colleagues ${ }^{22}$ reported the first results of ATOMS procedure in a prospective, non-randomized, multicentre study. A total of 99 patients with a mean age of 70.4 underwent placement of the ATOMS device at 9 European urological centres with an average follow-up of 17.8 months. The most common indications for placement of the adjust- 


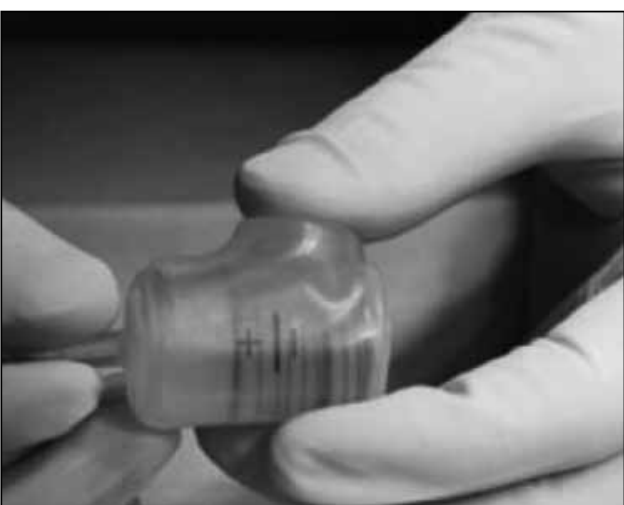

Fig. 9. Pump button for activation ZSI 375 artificial urinary.

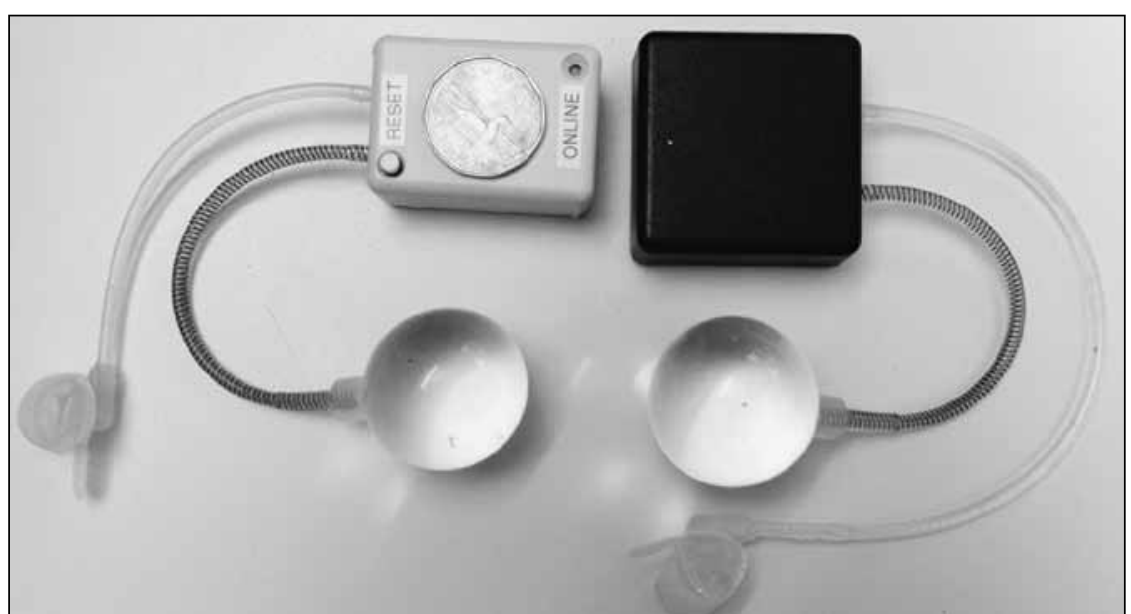

Fig. 10. The novel, remotely-controlled artificial urinary sphincter. able male system were SUI after RP (92/99 patients, 92.9\%) and failure after previous surgeries (34/99 patients, 34.3\%). Some of the previous devices (Pro-ACT, Argus [Promedon], AMS800, Flow-Secure [ZEPHYR Surgical Implants Inc.]) were explanted at least 3 months before the implantation of the ATOMS device. A total of $31 / 99$ patients (31.3\%) presented after secondary radiation.

Primary outcome variables included changes in usage of pad/24-hour and differences in pad test/24-hour before and after the operation. Secondary outcome variables were related to the safety of the procedure, such as urinary retention, bladder or urethral injuries, pain and infections.

The mean number of adjustments to reach the desired result was 3.8. The mean pad use decreased significantly from 7.1 to 1.3 pads/24-hours $(p<0.001)$. In the end, $63 \%$ patients were considered dry $(0 \mathrm{pad},<10 \mathrm{~mL}$ at the 24-hour pad test) and 29\% were improved (1-2 pads/24hours, $10-40 \mathrm{~mL}$ at the 24 -hour pad test), resulting in a calculated overall success rate of $92 \%$. However, $8 \%$ of the patients had $>3$ pads/24-hours $(>40 \mathrm{~mL}$ at the 24 -hour pad test) and were considered as failed. All patients reported an improvement in quality of life in all domains of the SF-36.

The most frequently reported complications were transient pain or numbness referred to the perineum, scrotum or thighs. This transient complication was reported by $68.7 \%$ of patients and resolved gradually after using non-opioid analgesics for 3 to 4 weeks, but no system had to be explanted for this reason. There were no cases of infection at the site of mesh implantation or in the perineal area, while a wound infection at the site of the titanium port occurred in 4/99 patients $(4.0 \%) 10$ to 68 days after surgery, leading to complete explantation of the device. All patients received a reimplantation of the ATOMS device after 3 months. There were no urethral or bladder injuries, erosions or migrations of components related to the device.

\section{Artificial urinary sphincter}

\section{The ZSI 375 artificial urinary}

To facilitate AUS implantation, a new device, the ZSI 375 (Zephyr Surgical Implants Geneva, Switzerland) has been developed. The ZSI 375 device works like a typical hydraulic AUS. It is a one-piece device made up of 2 parts connected by kink-resistant tubing. One part is an adjustable cuff moulded to fit around the urethra; the other is a pressureregulating tank and pump that is placed in the scrotum (Fig. 8). The device has 2 circuits: a hydraulic circuit and a compensation pouch circuit, separated by a spring-regulated piston in the tank. It is supplied with a $5-\mathrm{mL}$ syringe and 2 Huber needles. Before its use, one must inject $4.5 \mathrm{~mL}$ of saline via the cuff septum to fill the hydraulic circuit. After use, the compensation pouch is then filled with $4.5 \mathrm{~mL}$ of saline, and, importantly, the device is deactivated.

A traditional surgical technique was used consisting of a perineal incision for cuff placement and a scrotal incision for pump and tank placement. A 14- or 16-F Foley urethral catheter was placed for guidance. After setting the sphincter closure pressure range $\left(60-70,70-80\right.$ or $90-100 \mathrm{cmH}_{2} \mathrm{O}$ ) using the spring, the pump unit was placed in the scrotal compensation pouch. Pressure could be increased in situ by trans-scrotal injection of saline into the pouch; $1 \mathrm{~mL}$ of saline increased pressure by about $10 \mathrm{cmH}_{2} \mathrm{O}$ (range: 8-12). Patients were discharged once they could void spontaneously. The device was activated 8 weeks later by pushing the activation button (Fig. 9). To void, patients had to squeeze and release the pump button. The saline solution drawn from the cuff unit into the pump unit released the pressure around the urethra. The cuff automatically re-inflated within 150 seconds. 
Staerman and colleagues ${ }^{23}$ performed a retrospective analysis of 36 consecutive patients (mean age: 63) who underwent ZSI 375 placement for moderate-to-severe SUI after RP $(n=28)$, TURP $(n=6)$ or bladder replacement $(n=2)$. The perineal plus scrotal approach was used in 32 patients and the perineal approach only was used in 4 patients. The mean hospital stay was 3 days and the median follow-up was 15.4 months.

At 3 and 6 months after implantation, 28 (78\%) and 26 (73\%) of the 36 patients, respectively, used 0 or just 1 pad per day (social continence). No patient experienced bladder overactivity, chronic urinary retention, or any other adverse effect after device activation. Two patients presented with urinary retention after catheter removal and required placement of a supra-pubic catheter until healing and before pump-handling.

Complications leading to device removal arose in 4/36 patients ( 1 case of erosion and 3 of infection). The case of erosion arose in 1 of the 2 patients with urinary retention after catheter removal. Infection in 1 patient was secondary to urethral injury during the procedure; the device was removed 5 days after implantation. Two patients, one with a thick scrotum, had pump implantation via a perineal incision. They encountered problems with pump manipulation and underwent a second procedure for pump placement in another subdartos scrotal pouch via a scrotal incision. One of these patients presented with a trans-scrotal extrusion of the pump unit. The device was removed in both patients.

\section{A novel remotely-controlled, artificial urinary sphincter}

Corcos and colleagues developed a new sphincter using an AMS800 to replace the pump. The new electronic pump has been designed as small as possible to facilitate its implantation beside the reservoir and to be compatible with the existing AMS800 tubing, cuff and balloon. ${ }^{24}$ They integrated a minimal number of components to minimize power consumption and reduce failure risk and production cost. The device is extremely compact and totally wireless (Fig. 10). The prototype has been tested on a fresh pig's bladder and total continence was demonstrated.

\section{The new devices}

\section{The Virtue quadratic sling}

The Virtue quadratic sling (Coloplast, Humlebaek, Denmark) is a new device that combines a transobturator and prepubic surgical approach. It was developed to treat PPI and consists of a large pore knitted monofilament polypropylene mesh with 2 pre-attached inferior (transobturator) extensions and 2 superior (prepubic) extensions (Fig. 11) without the risks of bone screws or retropubic needle passage.
Comiter and colleagues ${ }^{25}$ described a standardized procedure for the placement of the Virtue quadratic. In their study of 22 consecutive men who had SUI after RP, they evaluated the resistance of the sling to leakage via measurement of retrograde leak point pressure (RLPP) during key intraoperative steps. The mean patient age was 70 . The mean RLPP baseline was $33.4 \pm 8.8 \mathrm{~cm}$ water. After transobturator tensioning, the mean RLPP increased to $43.3 \pm 6.8 \mathrm{~cm}$ water. After prepubic tensioning, the mean RLPP was $55.8 \pm 8.7$, and the final RLPP after transobturator and prepubic fixation increased to $68.8 \pm 6.0 \mathrm{~cm}$ water. Each mean retrograde leak point pressure value was significantly higher than the preceding value. ${ }^{25}$

\section{Periurethral constrictor}

The periurethral constrictor (Silimed) consists of a cuff linked to a self-sealing valve (Fig. 12). The cuff is made of a silicone membrane and is designed to allow for adjustment around the proximal urethra. A silicone tube links the self-sealing valve to the cuff. The injection of sterile saline solution in the self-sealing valve partially occludes the proximal urethra, increasing the outlet pressure.

Comiter and colleagues ${ }^{25}$ assessed the 1 -year safety and efficacy of the device in a cohort of 66 patients with severe incontinence (defined as the need for $\geq 3$ PPD) post-RP. Continence was recovered totally in 49 cases $(79 \%)$, partially in 9 cases (1 PPD in 5 patients, 2 PPD in 3 patients), and remained unchanged in 4 patients ( $\geq 3$ PPD). No one needed self-catheterization to empty the bladder. No grade IV or $\mathrm{V}$ complications occurred, according to Clavien Dindo classification. Seven (11\%) IIla-b complications were registered. It was necessary to remove the device in 4 cases (6\%): 2 for infection of the device and 2 for urethral erosion and consequent urinary fistula. The self-sealing valve was replaced successfully in 3 of the malfunctioning cases $(4.5 \%) .25,26$

\section{Discussion}

SUI following RP has been described as a major adverse effect affecting quality of life and remains a daily challenge for urologists. After initial assessment, the first-line treatment is non-invasive, based on supervised pelvic floor muscle training. ${ }^{2}$ Behavioural therapies are also recommended, $, 27,28$ although no high level-of-evidence work has established their efficiency. ${ }^{27}$ In the case of refractory SUI, more specialized management using invasive options are recommended.

An effective drug treatment with acceptable adverse effect is needed to fill the gap between physical/behavioural therapies and surgical options. For the first time in a RCT on PPI, duloxetine was shown to be effective. ${ }^{15}$ Indeed, the authors were able to show that this serotonin- norepinephrine reuptake inhibitor, at a dose of $80 \mathrm{mg}$ daily over a 3-month 


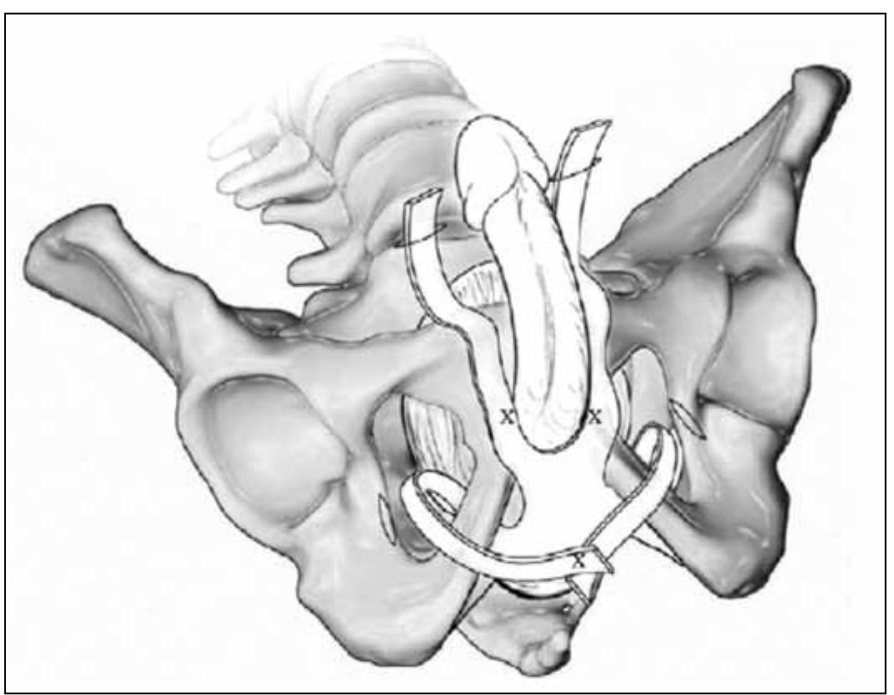

Fig. 11. The Virtue quadratic sling (Coloplast, Humlebaek, Denmark).

period, is superior to placebo and reduces the frequency of leakage episodes in patients with mild to moderate PPI. The treatment also induced a marked increase in quality of life. Thus, as an effective drug treatment with acceptable adverse effects, duloxetine could be a pharmacological alternative to physical or behavioural therapies and surgical options, as well as a useful treatment for patients who want to postpone or delay surgery. It may also provide a means to treat patients with incomplete results after minimally invasive therapy, such as sling and balloons. Nevertheless, the small number of subjects did limit the evidence for treatment efficacy, and it limited the interpretation of adverse events. Furthermore, duloxetine is not currently available in North America.

Although the AUS AMS800 has been considered the gold standard for the surgical treatment of non-neurological SUI in men, the quantity and level of evidence is low (level $2 \mathrm{~b}$ evidence as per the European Association of Urology guidelines). ${ }^{29}$ There are no well-designed prospective RCTs; most information is gained from older case series. ${ }^{30}$ Men considering insertion of an AUS should understand that they must be able to operate a scrotal pump, requiring adequate dexterity and cognitive function. If the ability of an individual to operate the pump is uncertain, it may not be appropriate to implant an AUS. In addition, Kumar and colleagues ${ }^{12}$ showed that many patients prefer treatment with a non-mechanical device. To retain good success rates and improve some disadvantages of the AUS AMS800, new devices have been developed and have generated an exponential number of recent publications.

There are no prospective RCTs to compare different surgical procedure. Most studies consist of prospective or retrospective case series, with variable follow-up, small sizes, and variable definitions and assessment of success. The patient baseline characteristics (severity of incontinence, history of

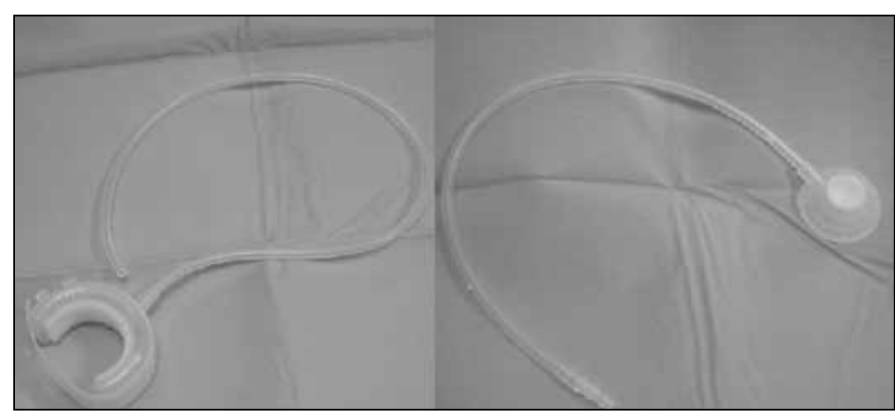

Fig. 12. Periurethral constrictor (Silimed).

adjuvant RT) were not strictly comparable to other studies and did not allow for a true head-to-head comparison. No study satisfied the International Consultation on Incontinence recommendation for the design of clinical research concerning implantable surgical devices (i.e., independent largescale prospective multicentre case series when RCTs are not feasible). ${ }^{28}$

In our present review, the success rates for surgical procedures is between $60 \%$ and $80 \%$ compared to $61 \%$ and to $100 \%$ with AUS AMS800 in a recent critical systematic review. ${ }^{31}$ In the Advance study, Rehder and colleagues ${ }^{18}$ have shown that the severity of incontinence significantly predicted outcomes, but severe incontinence was not an included criteria in AUS AMS800 studies.

There is no evidence that adjustability of the male sling offers additional benefit over other types of sling. However, the absence of erosion in the large cohort of patients in the transobturator sling (AdVance and ISTOP TOMS) studies ${ }^{17,18}$ would indicate the best safety profile compared to the balloons ProACT ${ }^{20}$ and the readjustable male sling (Argus system). Indeed, the balloons ProACT and the Argus sling are associated with high explantations rates $(18 \%$ and $15.8 \%$, respectively) for complications, ${ }^{16,20}$ whereas there is just a single case of explantation with transobturator slings.

More interesting, previous irradiation had no impact on outcome in the AdVance sling study, whereas a statistically significant correlation was observed between failure and a history of pelvic RT in the balloons ProACT study. ${ }^{20}$ In the Argus sling study, among 16 patients who had complications requiring device removal due to urethral erosion, 3 had been treated previously with RT. In the ISTOP sling trial, patients were excluded if they had a history of prostate RT. It remains controversial whether the results of the sling or balloons procedure are affected in irradiated cases.

The adjustable transobturator male system (ATOMS) was designed to resolve the problems associated with postoperative adjustement of male sling systems and the risk of urethral atrophy and erosion with AUS AMS800, which compresses the urethra circumferentially thereby interfering with venous blood flow. Indeed, the ATOMS device compresses only the dorsal aspects of the bulbar urethra, 
leaving the ventral and lateral blood flow intact. Moreover, the implantable titanium port can adjust the volume of the cushion at any time. Even if the results seem to be similar to those of AUS AMS800 with dryness rates of $63 \%,{ }^{22}$ its limitations were the non-randomized fashion and the short follow-up with a small number of patients $(n=99)$.

In addition, to facilitate AUS implantation, a new device, the ZSI 375 has been developed. The ZSI 375 has no abdominal reservoir so it can reduce operating time and avoid abdominal incision and dissection in scarred retroperitoneum. Moreover, it is pre-connected, and it has a cuff that can be adjusted around the urethra. Nevertheless, its limited effectiveness reduces its generalizability. ${ }^{23}$ Similarly, Corcos and colleagues developed a novel AUS offering the possibility to remotely control the pressure within the implant rapidly and without complex manipulation. ${ }^{24}$ Indeed, the functioning of AMS800 is purely hydro-mechanical applying a constant pressure around bulbous urethra. The common reasons why this device has been modified are: insufficient cuff pressure and urethral atrophy secondary to this constant pressure. Furthermore, its functioning requires some dexterity and therefore its use in some patients is limited.

\section{Conclusion}

New minimally invasive surgical procedures, such as the male sling and adjustable continence device, have emerged as the main alternative to AUS with social continence rates up to $60 \%$ despite a short follow-up. However, the balloons ProACT and the Argus sling are associated with high explantations rates (18\% and $15.8 \%$, respectively) due to complications. There are many cohort studies and case series, but only 1 RCT examining the pharmacological approach. There are no standardized protocols, outcomes measures, and definitions of UI severity and success of surgical procedure. Therefore, there is an urgent need for well-designed clinical trials to clarify the role of new surgical alternatives to manage PPI. New technologies should continue to be evaluated and compared with the AUS (AMS800), which remains the gold standard.

Competing interests: Dr. Caremel declares no competing financial or personal interests. Dr. Corcos is an Advisor for Allergan, Astellas and Waston. He is a consultant for Allergan, an Investigator for Astellas and a Speaker for Allergan.

This paper has been peer-reviewed.

\section{References}

1. Hu JC, Elkin EP, Pasta DJ, et al. Predicting quality of life after radical prostatectomy: Results from CaPSURE. J Urol 2004;171:703-8. http://dx.doi.org/10.1097/01.ju.0000107964.61300.f6

2. Rodriguez E, Skarecky DW, Ahlering TE. Post-robotic prostatectomy urinary continence: Characterization of perfect continence versus occasional dribbling in pad-free men. Urology 2006;67:785-8. http://dx.doi. org/10.1016/i.urology.2005.10.006

3. Krupski TL, Saigal CS, Litwin MS. Variation in continence and potency by definition. J Urol 2003;170:12914. http://dx.doi.org/10.1097/01.ju.0000085341.63407.46

4. Olsson LE, Salomon L, Nadu A, et al. Prospective patient-reported continence after laparoscopic radical prostatectomy. Urology 2001;58:570-2. http://dx.doi.org/10.1016/50090-4295(01)01261-4

5. Penson DF, McLerran D, Feng $Z$, et al. 5-year urinary and sexual outcomes after radical prostatectomy: Results from the prostate cancer outcomes study. J Urol 2005;173:1701-5. http://dx.doi. org/10.1097/01.ju.0000154637.38262.3a

6. Begg CB, Riedel ER, Bach PB, et al. Variations in morbidity after radical prostatectomy. N Engl J Med 2002;346:1138-44. http://dx.doi.org/10.1056/NEJMsa011788

7. Steineck G, Helgesen F, Adolfsson J, et al. Quality of life after radical prostatectomy or watchful waiting. N Engl J Med 2002;347:790-6. http://dx.doi.org/10.1056/NEJMoo021483

8. Stanford IL, Feng Z, Hamilton AS, et al. Urinary and sexual function after radical prostatectomy for clinically localized prostate cancer: the Prostate Cancer Outcomes Study. JAMA 2000;283:354-60. http:// dx.doi.org/10.1001/jama.283.3.354

9. Hunter KF, Glazener $C M$, Moore KN. Conservative management for postprostatectomy urinary incontinence. Cochrane Database Syst Rev 2007;2:CD001843.

10. Haijvassiliou CA. A review of the complications and results of implantation of the AMS artificial urinary sphincter. Eur Urol 1999;35:36-44. http://dx.doi.org/10.1159/000019817

11. Trigo Rocha F, Gomes $C M$, Mitre Al, et al. A prospective study evaluating the efficacy of the artificial sphincter AMS800 for the treatment of post radical prostatectomy urinary incontinence and the correlation between preoperative urodynamic and surgical outcomes. Urology 2008;71:85-9. http://dx.doi. org/10.1016/i.urology.2007.09.009

12. Kumar A, Litt ER, Ballert KN, et al. Artificial urinary sphincter versus male sling for post-prostatectomy incontinence-what do patients choose? J Urol 2009;18:1231-5. http://dx.doi.org/10.1016/i. juro.2008.11.022

13. Mariappan $P$, Ahasso A, Ballantyne $Z$, et al. Duloxetine, a serotonin and noradrenaline reuptake inhibitor (SNRI) for the treatment of stress urinary incontinence: a systematic review. Eur Urol 2007;51:67-74. http://dx.doi.org/10.1016/j.eururo.2006.08.041

14. Boy $S$, Reitz A, Wirth B, et al. Facilitatory neuromodulative effect of duloxetine on pudendal motor neurons controlling the urethral pressure: A functional urodynamic study in healthy women. Eur Urol 2006;50:119-25. http://dx.doi.org/10.1016/i.eururo.2005.12.020

15. Cornu JN, Merlet B, Ciofu C, et al. Duloxetine for mild to moderate postprostatectomy incontinence: Preliminary results of a randomised, placebo-controlled trial. Eur Urol 2011;59:148-54. http://dx.doi. org/10.1016/i.eururo.2010.10.031

16. Hübner WA, Gallistl H, Rutkowski M, et al. Adjustable bulbourethral male sling: Experience after 101 cases of moderate-to-severe male stress urinary incontinence. BJU Int 2011;107:777-82. http://dx.doi. org/10.1111/i.1464-410X.2010.09619.x

17. Grise P, Vautherin R, Nijnou-Ngninkeu B, et al. HOMme INContinence Study Group. I-STOP TOMS transobturator male sling, a minimally invasive treatment for post-prostatectomy incontinence: Continence improvement and tolerability. Urology 2012;79:458-63. http://dx.doi.org/10.1016/j.urology.2011.08.078

18. Rehder $\mathrm{P}$, Haab F, Cornu JN, et al. Treatment of postprostatectomy male urinary incontinence with the transobturator retroluminal repositioning sling suspension: 3- year follow-up. Eur Urol 2012;62:140-5. http://dx.doi.org/10.1016/i.eururo.2012.02.038

19. Hübner WA, Schlarp OM. Treatment of incontinence after prostatectomy using a new minimally invasive device: Adjustable continence therapy. BJU Int 2005;96:587-94. http://dx.doi.org/10.1111/j.1464410X.2005.05689.X

20. Rouprêt M, Misraï V, Gosseine PN, et al. Management of stress urinary incontinence following prostate surgery with minimally invasive adjustable continence balloon implants: Functional results from a single center prospective study. J Urol 2011;186:198-203. http://dx.doi.org/10.1016/i.juro.2011.03.016

21. Baver $W$, Karik M, Schramek P. The self-anchoring transobturator male sling to treat stress urinary incontinence in men: A new sling, a surgical approach and anatomical findings in a cadaveric study. BJU Int 2005;95:1364-6. http://dx.doi.org/10.1111/j.1464-410X.2005.05530.x

22. Hoda MR, Primus $G$, Fischereder $K$, et al. Early results of a European multicentre experience with a new self-anchoring adjustable transobturator system for treatment of stress urinary incontinence in men. BJU Int 2012;27. http://dx.doi.org/10.1111/i.1464-410X.2012.11482.x

23. Staerman $F$, G-Llorens $C$, Leon $P$, et al. ZSI 375 artificial urinary sphincter for male urinary incontinence: A preliminary study. BJU Int 2013;111:E202-6. 
24. Corcos J, Hached S, Loutochin 0 , et al. Novel, remotely-controlled, artificial urinary sphincter: A retrocompatible device. Proceedings of Annual Meeting of the American Urological Association (AUA) (April 4-8, 2013, San Diego)]: Abstract 1375.

25. Comiter $\mathrm{CV}$, Nitti V, Elliot C, et al. A new quadratic sling for male stress incontinence: Retrograde leak point pressure as a measure of urethral resistance. J Urol 2012;187:563-8. http://dx.doi.org/10.1016/i. juro.2011.09.152

26. Introini C, Naselli A, Zaninetta G, et al. Safety and efficacy of periurethral constrictor implantation for the treatment of post-radical prostatectomy incontinence. Urology 2012;79:1175-8. http://dx.doi. org/10.1016/j.urology.2011.11.065

27. Bauer RM, Bastian PJ, Gozzi C, et al. Postprostatectomy incontinence: All about diagnosis and management. Eur Urol 2009;55:322-33. http://dx.doi.org/10.1016/i.eururo.2008.10.029

28. Abrams $P$, Andersson KE, Birder L, et al. Fourth International Consultation on Incontinence Recommendations of the International Scientific Committee: Evaluation and Treatment of Urinary Incontinence, Pelvic Organ Prolapse, and Fecal Incontinence. Neurourolurodyn 2010;29:213-40. http://dx.doi.org/10.1002/ nau.20870
29. Lucas MG, Bosch RJ, Burkhard FC, et al. EAU guidelines on surgical treatment of urinary incontinence. Eur Urol 2012;62:1118-29. http://dx.doi.org/10.1016/i.eururo.2012.09.023

30. Herschorn $\mathrm{S}$, Brushini $\mathrm{H}$, Comiter $\mathrm{C}$, et al. Surgical treatment of urinary incontinence in men. Neurourol Urodyn 2010;29:179-90. hittp://dx.doi.org/10.1002/nau.20844

31. Van der Aa F, Drake MJ, Kasyan GR, et al.; for the Young Academic Urologist Functional Urology Group. The artificial urinary sphincter after a quarter of a century: A critical systematic review of its use in male nonneurogenic incontinence. Eur Urol 2012;187:563-8. http://dx.doi.org/10.1016/i.eururo.2012.11.034

Correspondence: Dr. Jacques Corcos, Department of Urology, Jewish General Hospital, 3755 Côte Sainte Catherine, Montréal, QC H3T 1E2; jcorcos@uro.jgh.mcgill.ca 